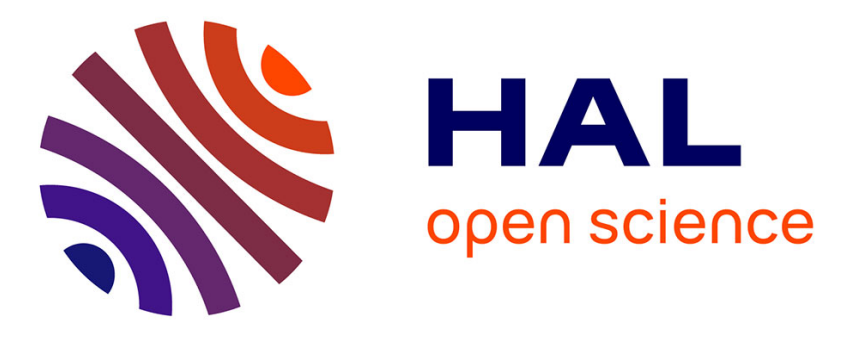

\title{
Damping analysis of beams submitted to passive and active control
}

\author{
Hakim Boudaoud, El Mostapha Daya, S. Belouttar, Laeticia Duigou, Michel \\ Potier-Ferry
}

\section{- To cite this version:}

Hakim Boudaoud, El Mostapha Daya, S. Belouttar, Laeticia Duigou, Michel Potier-Ferry. Damping analysis of beams submitted to passive and active control. Engineering Structures, 2009, 31 (2), pp.322-331. 10.1016/j.engstruct.2008.08.009 . hal-00402245

\section{HAL Id: hal-00402245 \\ https://hal.science/hal-00402245}

Submitted on 23 Jun 2018

HAL is a multi-disciplinary open access archive for the deposit and dissemination of scientific research documents, whether they are published or not. The documents may come from teaching and research institutions in France or abroad, or from public or private research centers.
L'archive ouverte pluridisciplinaire HAL, est destinée au dépôt et à la diffusion de documents scientifiques de niveau recherche, publiés ou non, émanant des établissements d'enseignement et de recherche français ou étrangers, des laboratoires publics ou privés. 


\title{
Damping analysis of beams submitted to passive and active control
}

\author{
H. Boudaoud ${ }^{\text {a,b }}$, E.M. Daya a ${ }^{\text {a }}$ S. Belouettar ${ }^{\text {b,*, }}$, L. Duigou ${ }^{c}$, M. Potier-Ferry ${ }^{\text {a }}$ \\ a Laboratoire de Physique et Mécanique des Matériaux, U.M.R. C.N.R.S. 7554, Université Paul Verlaine Metz. Ile du Saulcy, 57045, Metz, France bentre de Recherche Public Henri \\ Tudor. 29, Avenue John F. Kennedy, L-1855 Luxembourg, Luxembourg \\ c Laboratoire Génie Mécanique et Matériaux, Rue de Saint Maudé, B.P. 92116, 56321, Lorient Cedex, France
}

\begin{abstract}
In this paper an analytical method is proposed for damping analysis of sandwich beams with piezoelectric and viscoelastic layers. Based on the classical zig-zag model and some assumptions about the electric field, this method leads to an analytical expression of the modal loss factor and frequency. Considering two feedback control laws, the obtained hybrid damping of the sandwich beam is characterized. Numerical finite element applications are considered, in order to examine the efficiency and limitations of the presented method.
\end{abstract}

\section{Introduction}

Vibration suppression of structures is a problem in engineering science that has occupied researchers for a while. The methodology used can be categorized into two groups, namely passive and active controls. In passive control, the material properties of the structure, such as damping and stiffness, are modified so as to change the response of the structure. More than 40 years ago, it was well established that an efficient way to increase passive damping is the use of a sandwich construction with alternating elastic and viscoelastic layers [1,2]. Therefore, many analytical and numerical methods have been proposed to determine the damping parameters (loss factor and frequency) [3-5]. So, these modal parameters can be obtained in different ways, i.e., by the direct frequency response method [6], the complex eigenvalue method [7], the modal strain energy method [6,8], and the nonlinear complex eigenvalue techniques [9-11].

In active control, the structural response is controlled by adding an external effort to the structure. For two decades many researchers tried to gain benefit from coupling both control types in the so-called "hybrid vibration control". A detailed review

\footnotetext{
* Corresponding address: Laboratoire de Technologies Industrielles Centre de Recherche Public Henri Tudor. 29, Avenue John F. Kennedy, L-1855 Luxembourg, Luxembourg.

E-mail address: salim.belouettar@tudor.lu (S. Belouettar).
}

and assessment of hybrid damping treatments of structures, with focus on smart structures with piezoelectric control actuation, has been given by Rao [12]. Since the 1950's, there have been a lot of papers published on sandwich structures using passive damping. Excellent reviews on the evolution of modeling passive damping were given by Nakra [13-15], Torvik [16], Mead [17], and $\mathrm{Hu}$ [5]. More recently, many researchers, as Lee [18], Crawley [19], and Preumont [20], have provided governing equations, reciprocal relationships and experimental verification of the induced-strain actuation, for smart structures dealing with piezoelectric laminates and active control. Nevertheless, a widely made assumption is the use of a linearly varying electric field [21-23]. Concerning hybrid control, a large part of studies have highlighted structures with a hybrid arrangement called ACLD (SCLD) for active (smart) constrained layer damping [24-27]. In many theoretical and experimental investigations the active system increases the passive transverse shear deformation of the viscoelastic constrained layer and appears to be an effective means to control vibration [28]. From an analytical point of view, two- and three-dimensional solutions, in the case of simply supported sandwich beam and plates with piezoelectric layers, have been given by Heyliger [29], Vel [30], Cupial [31], and Franco Correia [32].

From this literature review there is no method for modal parameter calculations of structures with hybrid damping treatments. Indeed, when the material properties are viscoelastic and piezoelectric, the stiffness becomes complex and depends 

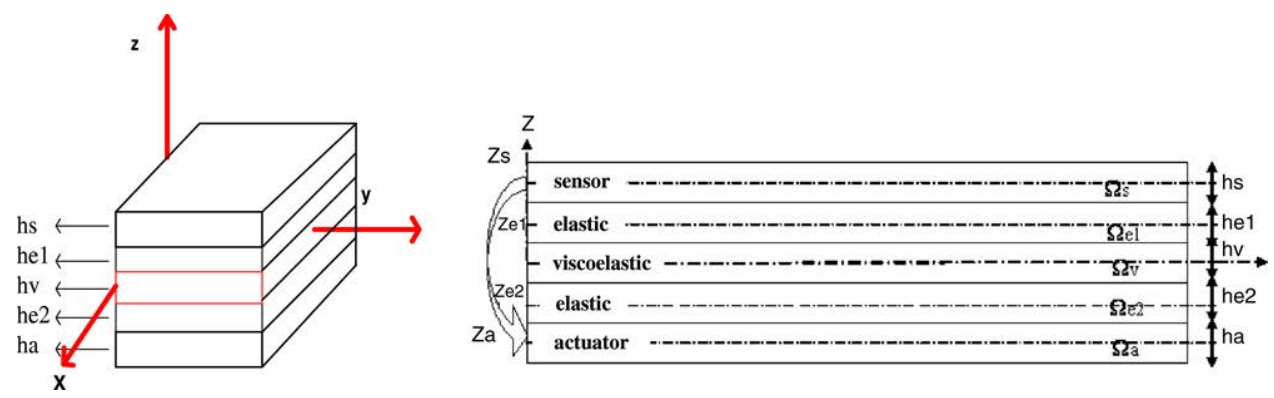

Fig. 1. Notations used for the piezoelectric/elastic/viscoelastic/elastic/piezoelectric beam.

non-linearly on the vibration frequency and on the active control. This method is similar to the one developed for piezoelectric/elastic/piezoelectric laminates by Duigou [33] in which the electrode effect has not been taken into account. In this paper an analytical analysis is proposed when the starting model is a piezoelectric/elastic/viscoelastic/elastic/piezoelectric sandwich beam. The structure is modeled with the zig-zag theory. Next the electromechanical problem is reduced to a purely mechanical problem using elastic and viscoelastic equivalent stiffness properties. The control strategy is based on a proportional direct feedback law or a velocity derivative feedback law. The effect of viscoelastic material damping and the effect of the piezoelectric material properties on modal vibration reduction are studied. The results are validated by comparison with a two-dimensional finite element simulation using the code ABAQUS [34].

\section{An electromechanical model for adaptive laminated beams}

In this part, a model for a piezoelectric/elastic/viscoelastic/ elastic/piezoelectric beam is presented. The geometry of the five-layer beam is depicted in Fig. 1. In view of analytical studies, this model is designed to be as simple as possible, including Euler-Bernoulli and Timoshenko kinematics and the assumption of transverse electric field. More precisely, each pair of elastic-piezoelectric layers is represented as an Euler-Bernoulli beam and the whole structure by the zig-zag theory to account for the shear in the central layer [4]. Various levels of approximations are discussed, as well as the treatment of the electrostatic problem in the sensor.

\subsection{Kinematic models}

To describe the properties of a sandwich piezoelectric/elastic/ viscoelastic/elastic/piezoelectric beam, Euler-Bernouilli assumptions are considered for the stiff layers and Timoshenko ones for the central one. The five layers have the same deflection $w$ and the stiff layers have the same rotations. So, the axial displacements in the different layers can be written in the following form:

$$
\left\{\begin{array}{l}
U_{i}(x, z)=u_{i}(x)-\left(z-z_{i}\right) w^{\prime}(x) \quad i=s, e_{1}, e_{2}, a \\
U_{v}(x, z)=u(x)+z \beta(x) .
\end{array}\right.
$$

The origin of $z$ axis is the medium plane and $z_{i}$ indicates the medium axis ordinate of each layer:

$z_{s}=-z_{a}=\left(h_{v}+2 h_{e}+h_{p}\right) / 2, \quad z_{e_{1}}=-z_{e_{2}}=\left(h_{v}+h_{e}\right) / 2 .(2)$

$u_{i}$ represents the axial displacement of the $i$ th layer and $u$ that of the central viscoelastic layer. $\beta$ is its rotation.

The displacement continuity conditions at the interfaces allow us to obtain the axial displacement field in terms of the axial displacement at the center $u$, of the rotation $\beta$ and of the deflection $w$. So, the axial strains of the different layers can be expressed:

$$
\left\{\begin{array}{l}
\varepsilon_{1 s}=u^{\prime}+\frac{h_{v}}{2} \beta^{\prime}-H w^{\prime \prime}-\left(z-z_{s}\right) w^{\prime \prime} \\
\varepsilon_{1 e_{1}}=u^{\prime}+\frac{h_{v}}{2} \beta^{\prime}-\frac{h_{e}}{2} w^{\prime \prime}-\left(z-z_{e_{1}}\right) w^{\prime \prime} \\
\varepsilon_{1 v}=u^{\prime}+z \beta^{\prime} \\
\varepsilon_{1 e_{2}}=u^{\prime}-\frac{h_{v}}{2} \beta^{\prime}+\frac{h_{e}}{2} w^{\prime \prime}-\left(z-z_{e_{2}}\right) w^{\prime \prime} \\
\varepsilon_{1 a}=u^{\prime}-\frac{h_{v}}{2} \beta^{\prime}+H w^{\prime \prime}-\left(z-z_{a}\right) w^{\prime \prime}
\end{array}\right.
$$

where

$H=\frac{h_{p}}{2}+h_{e}$.

\subsection{Layer generalized constitutive equations}

Let us assume that the elastic and viscoelastic materials are linear, homogenous and isotropic. Each layer is considered as an Euler-Bernoulli beam, except the central layer, where Timoshenko kinematics and constant shear stress assumption hold. According to Hooke's law and to the kinematical relations (Eqs. (1) and (2)), one defines the axial force $N$, the bending moments $M$ of the elastic or viscoelastic layers, and the shear force $T$ of the core, as follows:

$$
\begin{array}{ll}
N_{e_{1}}=E_{e} S_{e}\left(u^{\prime}+\frac{h_{v}}{2} \beta^{\prime}-\frac{h_{e}}{2} w^{\prime \prime}\right) & M_{e 1}=E_{e} I_{e_{1}} w^{\prime \prime} \\
N_{e_{2}}=E_{e} S_{e}\left(u^{\prime}-\frac{h_{v}}{2} \beta^{\prime}+\frac{h_{e}}{2} w^{\prime \prime}\right) & M_{e 2}=E_{e} I_{e_{2}} w^{\prime \prime} \\
N_{v}=S_{v} Y * \dot{u}^{\prime} & M_{v}=I_{v} Y * \dot{\beta}^{\prime} \\
T=\frac{S_{v}}{2\left(1+v_{v}\right)} Y *\left(\dot{w}^{\prime}+\dot{\beta}\right) &
\end{array}
$$

where $*$ denotes the convolution product, $Y$ is the relaxation function, $E_{i}$ is the Young's modulus, $v_{i}$ the Poisson ratio, $I_{i}$ the quadratic moment, and $S_{i}$ the cross-section area of the considered $i$ th layer.

Piezoelectric materials have the capacity to act or react to an electric field or a strain. This property results in the following constitutive equation:

$$
\left\{\begin{array}{l}
\sigma=\mathbf{c} \varepsilon-\mathbf{e}^{t} \mathbf{E} \\
\mathbf{D}=\mathbf{e} \varepsilon+\epsilon \mathbf{E}
\end{array}\right.
$$

where $\sigma, \varepsilon, \mathbf{D}$, and $\mathbf{E}$ are the stress and strain tensors, electric displacement vector, and field vector, respectively. c, e, and $\boldsymbol{\epsilon}$ are the elasticity matrix, the piezoelectric matrix and the dielectric permittivity. The coefficients of the elasticity matrix are measured at a constant electric field and the components of the permittivity matrix are measured at constant strain. 
The orthotropic piezoelectric materials are poled in the thickness direction and the extension mechanism is considered. The constitutive equations can be represented in terms of a reduced number of components with respect to 1-2-3 axes of the piezoelectric material. We suppose that the piezoelectric layers are thin, the stress tensor is uniaxial, and the electric fields $\mathbf{D}$ and $\mathbf{E}$ are parallel to the transverse direction. So, the constitutive equations are reduced as in De [35] to

$\left\{\begin{array}{l}\sigma_{1} \\ D_{3}\end{array}\right\}=\left[\begin{array}{cc}c_{11}^{*} & -e_{31}^{*} \\ e_{31}^{*} & \epsilon_{33}^{*}\end{array}\right]\left\{\begin{array}{l}\varepsilon_{1} \\ E_{3}\end{array}\right\}$

where

$\left\{\begin{array}{l}\epsilon_{33}^{*}=\epsilon_{33}+\frac{e_{33}^{2}}{c_{33}} \\ e_{31}^{*}=e_{31}-\frac{c_{13}}{c_{33}} e_{33} \\ c_{11}^{*}=c_{11}-\frac{c_{13}^{2}}{c_{33}} .\end{array}\right.$

The relation between the electric field and the electric potential can be reduced to the following:

$E_{3}=-\frac{\partial \phi(x, z)}{\partial z}$.

In this analysis, we consider that the central layer is conductive with a uniform potential, fixed to zero [36]. Often in the literature, the electric field is assumed to be linearly varying across the thickness, in accordance with the same variation about stress and strain [21-23]. Here, we assume thin piezoelectric layers. This yields a constant electric field through the thickness of each piezoelectric layer:

$E_{3}=-\frac{\phi(x)}{h}$

where $\phi(x)$ is the superficial potential. $h$ is the thickness of the piezoelectric layer.

So, from the expression (Eq. (3)), one defines the axial forces $N$ and the bending moments $M$ in the piezoelastic layers as follows:

$N_{s}=c_{11}^{*} S_{p}\left(u^{\prime}+\frac{h_{v}}{2} \beta^{\prime}-H w^{\prime \prime}\right)+e_{31}^{*} \frac{S_{p}}{h_{p}} \phi_{s}(x)$

$M_{s}=c_{11}^{*} I_{s} w^{\prime \prime}$

$N_{a}=c_{11}^{*} S_{p}\left(u^{\prime}-\frac{h_{v}}{2} \beta^{\prime}+H w^{\prime \prime}\right)-e_{31}^{*} \frac{S_{p}}{h_{p}} \phi_{a}(x)$

$M_{a}=c_{11}^{*} I_{a} w^{\prime \prime}$

with $I_{i}=\int_{S_{i}}\left(z-z_{i}\right)^{2} \mathrm{~d} S$

$i=s, a$

where $S_{i}$ is the section area of each $i$ th layer.

\subsection{Electromechanical constitutive equations of the sandwich beam}

In accordance with zig-zag kinematics, the beam stresses can be represented by a global normal force $N$, by global moments $M_{\beta}$ and $M_{w}$ and by a shear force. Thus the virtual work of internal forces is in the following form:

$\delta W_{\text {int }}=\int_{0}^{L}\left\{N \delta u^{\prime}+M_{w} \delta w^{\prime \prime}+M_{\beta} \delta \beta^{\prime}+T\left(\delta \beta+\delta w^{\prime}\right)\right\} \mathrm{d} x$

where $N, M_{\beta}, M_{w}$ and $T$ are defined as

$N=N_{s}+N_{e 1}+N_{v}+N_{e 2}+N_{a}$,

$M_{\beta}=\frac{h_{v}}{2}\left(N_{e_{1}}-N_{e_{2}}\right)+M_{v}+\frac{h_{v}}{2}\left(N_{s}-N_{a}\right)$,

$M_{w}=M_{s}+M_{e_{1}}+M_{e_{2}}+M_{a}-\frac{h_{e}}{2}\left(N_{e_{1}}-N_{e_{2}}\right)-H\left(N_{s}-N_{a}\right)$

$T=\frac{S_{v}}{2\left(1+v_{v}\right)} Y *\left(\dot{w}^{\prime}+\dot{\beta}\right)$. with

$N_{i}=\int_{S_{i}} \sigma_{i} \mathrm{~d} S$

$M_{i}=\int_{S_{i}}\left(z-z_{i}\right) \sigma_{i} \mathrm{~d} S$.

By neglecting the rotational inertia, the Principle of d'Alembert can be written as in [37]

$$
\begin{aligned}
& \int_{0}^{L}\left\{N \delta u^{\prime}+M_{w} \delta w^{\prime \prime}+M_{\beta} \delta \beta^{\prime}+T\left(\delta \beta+\delta w^{\prime}\right)\right. \\
& \left.+(\rho S)_{e q}\left(\frac{\partial^{2} u}{\partial t^{2}} \delta u+\frac{\partial^{2} w}{\partial t^{2}} \delta w\right)\right\} \mathrm{d} x=0 \quad \forall \delta u, \delta w, \delta \beta
\end{aligned}
$$

where

$$
(\rho S)_{e q}=\rho_{s} S_{s}+\rho_{e 1} S_{e 1}+\rho_{v} S_{v}+\rho_{e 2} S_{e 2}+\rho_{a} S_{a} .
$$

$\rho_{i}$ and $S_{i}$ are respectively the density and the section area of layer $i$. We consider a viscoelastic core that is thin and soft. So, $M_{v}$ and $N_{v}$ can be neglected [38]. By combining Eqs. (11), (4) and (9), the global electromechanical constitutive equations of the laminate are deduced:

$$
\left\{\begin{array}{l}
N=(E S)_{\text {mec }} u^{\prime}+e_{31}^{*} \frac{S_{p}}{h_{p}}\left(\phi_{s}(x)-\phi_{a}(x)\right) \\
M_{\beta}=(E I)_{\beta} \beta^{\prime}+\gamma_{w} w^{\prime \prime}+e_{31}^{*} \frac{h_{v}}{2} \frac{S_{p}}{h_{p}}\left(\phi_{s}(x)+\phi_{a}(x)\right) \\
M_{w}=\gamma_{w} \beta^{\prime}+(E I)_{\text {mec }} w^{\prime \prime}-e_{31}^{*} H \frac{S_{p}}{h_{p}}\left(\phi_{s}(x)+\phi_{a}(x)\right) \\
T=\frac{S_{v}}{2\left(1+v_{v}\right)} Y *\left(\dot{w}^{\prime}+\dot{\beta}\right)
\end{array}\right.
$$

with

$$
\left\{\begin{array}{l}
(E S)_{\text {mec }}=2 E_{e} S_{e}+2 c_{11}^{*} S_{p} \\
(E I)_{\text {mec }}=E_{e}\left(I_{e 1}+I_{e 2}+\frac{h_{e}^{2}}{2} S_{e}\right)+c_{11}^{*}\left(I_{a}+I_{s}+2 H^{2} S_{p}\right) \\
\gamma_{w}=-\frac{h_{v}}{2}\left(h_{e} S_{e} E_{e}+2 c_{11}^{*} S_{p} H\right) \\
(E I)_{\beta}=\frac{h_{v}^{2}}{2}\left(E_{e} S_{e}+c_{11}^{*} S_{p}\right) .
\end{array}\right.
$$

Notice that there are no membrane/bending coupling terms because of the symmetrical multi-layer construction.

\subsection{Condensation of electric sensor potential}

We suppose no electric displacement in the piezoelectric sensor and the displacement is supposed constant through-the-thickness, leading to

$D_{3}\left(z_{s}\right)=e_{31}^{*} * \varepsilon_{1 s}\left(z_{s}\right)-\epsilon_{33}^{*} * \frac{\phi_{s}(x)}{h_{p}}=0$.

The sensor potential $\phi_{s}(x)$ is obtained as a function of the kinematic variables:

$\phi_{s}(x)=\frac{e_{31}^{*}}{\epsilon_{33}^{*}} h_{p}\left(u^{\prime}+\frac{h_{v}}{2} \beta^{\prime}-H w^{\prime \prime}\right)$.

Considering the relation (Eq. (18)) one eliminates the sensor electric potential in Eq. (15). This leads to a modified constitutive law:

$$
\left\{\begin{array}{l}
N=(E S)_{e q} u^{\prime}+\alpha \frac{h_{v}}{2} \beta^{\prime}-\alpha H w^{\prime \prime}-e_{31}^{*} \frac{S_{p}}{h_{p}} \phi_{a}(x) \\
M_{\beta}=\alpha \frac{h_{v}}{2} u^{\prime}+(E I)_{\beta e q} \beta^{\prime}+\gamma_{w e q} w^{\prime \prime}+e_{31}^{*} \frac{h_{v}}{2} \frac{S_{p}}{h_{p}} \phi_{a}(x) \\
M_{w}=-\alpha H u^{\prime}+\gamma_{w e q} \beta^{\prime}+(E I)_{e q} w^{\prime \prime}-e_{31}^{*} H \frac{S_{p}}{h_{p}} \phi_{a}(x)
\end{array}\right.
$$


with

$$
\left\{\begin{array}{l}
(E S)_{e q}=(E S)_{m e c}+\alpha \\
(E I)_{e q}=(E I)_{m e c}+\alpha H^{2} \\
\gamma_{w e q}=\gamma_{w}-\frac{h_{v}}{2} H \alpha \\
(E I)_{\beta e q}=(E I)_{\beta}+\left(\frac{h_{v}}{2}\right)^{2} \alpha
\end{array} \quad \alpha=\frac{e_{31}^{2} *}{\epsilon_{33} *} S_{p} .\right.
$$

Two coupling terms appear in Eqs. (19) and (20). The $\alpha$ term in $\gamma_{\text {weq }}$ represents the bending/rotation coupling term of electric origin. The membrane/bending coupling term $\left(-\alpha H\right.$ in $N$ and $\left.M_{w}\right)$ is due to the condensation of the sensor electric potential.

Formulas (Eq. (19)) can be expressed in the following matrix form:

$$
\left[\begin{array}{c}
N \\
M_{\beta} \\
M_{w}
\end{array}\right]=[C]\left[\begin{array}{c}
u^{\prime} \\
\beta^{\prime} \\
w^{\prime \prime}
\end{array}\right]+e_{31}^{*} \frac{S_{p}}{h_{p}} \phi_{a}(x)\left[V_{a}\right]
$$

with

$$
[C]=\left[\begin{array}{ccc}
(E S)_{e q} & \alpha \frac{h_{v}}{2} & -\alpha H \\
\alpha \frac{h_{v}}{2} & (E I)_{\beta e q} & \gamma_{w e q} \\
-\alpha H & \gamma_{w e q} & (E I)_{e q}
\end{array}\right] \text { and }\left[V_{a}\right]=\left[\begin{array}{c}
-1 \\
\frac{h_{v}}{2} \\
-H
\end{array}\right] \text {. }
$$

The $[C]$ matrix is real and symmetric. It brings out the membrane/bending coupling term due to the condensation of the electrostatic equation in the sensor electric potential.

\subsection{Accounting for electrode effect}

We consider now a practical case which supposes that two electrodes are bonded on the upper and lower piezoelectric layers. These electrodes lead to an additional equipotentiality boundary condition. Considering as formerly that there is no electric displacement in the piezoelectric sensor, and using the equipotentiality condition, one gets a new system of equations:

$\int_{0}^{L} D_{3}\left(z_{s}\right) \mathrm{d} x=\int_{0}^{L}\left(e_{31}^{*} * \varepsilon_{1 s}\left(z_{s}\right)-\epsilon_{33}^{*} * \frac{\phi_{s}(x)}{h_{p}}\right) \mathrm{d} x=0$

$\frac{\partial \phi_{s}(x)}{\partial x}=0$.

The sensor potential $\phi_{s}(x)$ is obtained here as a mean of the kinematic variables:

$\phi_{s}=\frac{e_{31}^{*}}{\epsilon_{33}^{*}} h_{p} \int_{0}^{L}\left(u^{\prime}+\frac{h_{v}}{2} \beta^{\prime}-H w^{\prime \prime}\right) \mathrm{d} x$.

Considering the relation (Eq. (24)), one eliminates the sensor electric potential in Eq. (15). This leads to a modified constitutive law:

$$
\left\{\begin{array}{l}
N=(E S)_{m e c} u^{\prime}+\alpha \int_{0}^{L}\left(u^{\prime}+\frac{h_{v}}{2} \beta^{\prime}-H w^{\prime \prime}\right) \mathrm{d} x-e_{31}^{*} \frac{S_{p}}{h_{p}} \phi_{a} \\
M_{\beta}=\alpha \frac{h_{v}}{2} \int_{0}^{L}\left(u^{\prime}+\frac{h_{v}}{2} \beta^{\prime}-H w^{\prime \prime}\right) \mathrm{d} x+(E I)_{\beta} \beta^{\prime} \\
\quad+\gamma_{w} w^{\prime \prime}+e_{31}^{*} \frac{h_{v}}{2} \frac{S_{p}}{h_{p}} \phi_{a} \\
M_{w}=-\alpha H \int_{0}^{L}\left(u^{\prime}+\frac{h_{v}}{2} \beta^{\prime}-H w^{\prime \prime}\right) \mathrm{d} x+\gamma_{w} \beta^{\prime} \\
\quad+(E I)_{m e c} w^{\prime \prime}-e_{31}^{*} H \frac{S_{p}}{h_{p}} \phi_{a} .
\end{array}\right.
$$

\subsection{Accounting for feedback control}

We will consider two different feedback control laws. The first one is a direct proportional control law:

$\phi_{a}(x)=G_{d} \phi_{s}(x)$

where $G_{d}$ is the direct control gain value. Using this control law leads to the following form for the constitutive law:

$\left[\begin{array}{c}N \\ M_{\beta} \\ M_{w}\end{array}\right]=\left([C]+g\left[V_{a}\right] \cdot\left[V_{s}\right]^{t}\right)\left[\begin{array}{c}u^{\prime} \\ \beta^{\prime} \\ w^{\prime \prime}\end{array}\right]$

with

$\left[V_{s}\right]=\left[\begin{array}{c}1 \\ h_{v} \\ 2 \\ -H\end{array}\right]$ and $g=G_{d} \alpha$. law:

The second feedback law is a negative velocity feedback control

$\phi_{a}(x)=-G_{v} \dot{\phi_{s}}(x)$

where $G_{v}$ is the velocity control gain value. Considering (Eq. (18)), the feedback control law leads to the following form for the constitutive law (here $g=G_{v} \alpha$ ):

$$
\left[\begin{array}{c}
N \\
M_{\beta} \\
M_{w}
\end{array}\right]=[C]\left[\begin{array}{c}
u^{\prime} \\
\beta^{\prime} \\
w^{\prime \prime}
\end{array}\right]-g\left[V_{a}\right] \cdot\left[V_{s}\right]^{t}\left[\begin{array}{c}
\dot{u}^{\prime} \\
\dot{\beta}^{\prime} \\
\dot{w}^{\prime \prime}
\end{array}\right] .
$$

Finally, equivalent beam constitutive models (Eqs. (27) and (30)) are derived, that account first for an analytical solution of the electric problem in the sensor layer and then for the control law in the actuator layer. The first equation (Eq. (21)) is a sort of elastic law, but without any symmetry of the matrix since $V_{a}$ is different from $V_{s}$. This lack of symmetry is due to the nonconservative character of the control law (Eq. (26)). Eq. (30) is similar to a Kelvin viscoelasticity law. Nevertheless, the damping matrix $g\left[V_{a}\right]\left[V_{s}\right]^{t}$ does not have a definite sign. As an outcome, the dynamical problem may be not well posed as in [33]. The latter consequence does not constitute a shortcoming for law frequency analysis.

Moreover, if one considers the practical case with an electrode effect one gets a similar expression for the proportional control law:

$$
\left[\begin{array}{c}
N \\
M_{\beta} \\
M_{w}
\end{array}\right]=\left[C_{\text {elastic }}\right]\left[\begin{array}{c}
u^{\prime} \\
\beta^{\prime} \\
w^{\prime \prime}
\end{array}\right]+\alpha\left[V_{\text {equi }}\right] \int_{0}^{L}\left(u^{\prime}+\frac{h_{v}}{2} \beta^{\prime}-H w^{\prime \prime}\right) \mathrm{d} x
$$

where

$$
\begin{gathered}
{\left[C_{\text {elastic }}\right]=\left[\begin{array}{ccc}
(E S)_{e q} & 0 & 0 \\
0 & (E I)_{\beta} & \gamma_{w} \\
0 & \gamma_{w} & (E I)_{\text {mec }}
\end{array}\right]} \\
\text { and }\left[V_{\text {equi }}\right]=\left[\begin{array}{c}
1-G_{d} \\
1+G_{d} \\
-1-G_{d}
\end{array}\right]
\end{gathered}
$$

and for the velocity feedback control law

$$
\begin{aligned}
{\left[\begin{array}{c}
N \\
M_{\beta} \\
M_{w}
\end{array}\right]=} & {\left[C_{\text {elastic }}\right]\left[\begin{array}{c}
u^{\prime} \\
\beta^{\prime} \\
w^{\prime \prime}
\end{array}\right]+[A] \int_{0}^{L}\left(u^{\prime}+\frac{h_{v}}{2} \beta^{\prime}-H w^{\prime \prime}\right) \mathrm{d} x } \\
& +[\Gamma] \int_{0}^{L}\left(\dot{u}^{\prime}+\frac{h_{v}}{2} \dot{\beta}^{\prime}-H \dot{w}^{\prime \prime}\right) \mathrm{d} x
\end{aligned}
$$


with

$[A]=\alpha\left[\begin{array}{c}1 \\ 1 \\ -1\end{array}\right]$ and $[\Gamma]=\alpha G_{v}\left[\begin{array}{c}-1 \\ 1 \\ -1\end{array}\right]$.

\section{An analytical analyses of damping properties}

In order to define the damping properties of the sandwich beam we consider free harmonic vibrations. The unknowns $u, w, \beta, N$, $M_{\beta}, M_{w}$, and $T$ are assumed in harmonic form ( $\omega$ is the frequency and can be complex):

$u=u \mathrm{e}^{\mathrm{i} \omega t}, \quad w=w \mathrm{e}^{\mathrm{i} \omega t}, \quad \beta=\beta \mathrm{e}^{\mathrm{i} \omega t}$

$N=N \mathrm{e}^{\mathrm{i} \omega t}, \quad M_{w}=M_{w} \mathrm{e}^{\mathrm{i} \omega t}, \quad M_{\beta}=M_{\beta} \mathrm{e}^{\mathrm{i} \omega t}$,

$T=T \mathrm{e}^{\mathrm{i} \omega t}$.

In this case, the viscoelastic material constitutive equation can be defined by a complex Young's modulus $E_{v}(\omega)$, that is frequency dependent. So, the shear force $T$ is written in the following form:

$T=G_{v}(\omega) S_{v}\left(w^{\prime}+\beta\right)$

where $G_{v}(\omega)=\frac{E_{v}(\omega)}{2\left(1+\nu_{v}\right)}$ is the complex shear modulus, which depends on $\omega$. The modal problem, which is defined from (Eq. (13)), becomes

$\int_{0}^{L}\left[\begin{array}{lll}N & M_{\beta} & M_{w}\end{array}\right]\left[\begin{array}{c}\delta u^{\prime} \\ \delta \beta^{\prime} \\ \delta w^{\prime \prime}\end{array}\right]+T\left(\delta \beta+\delta w^{\prime}\right)$

$-(\rho S)_{e q} \omega^{2}(u \delta u+w \delta w) \mathrm{d} x=0 \quad \forall \delta u, \delta w, \delta \beta$.

The modal loss factor $\eta$ and the frequency $\Omega$ can be obtained in a classical way [38]:

$\omega^{2}=\Omega^{2}(1+\mathrm{i} \eta)$.

To get an analytical solution, a simply supported beam is considered ( $N=0, w=0, M_{w}=0, M_{\beta}=0$ at the extremities). In this case the closed forms of the modes are

$w=W \sin (k x) \quad \beta=B \cos (k x) \quad u=U \cos (k x)$

$k=\frac{n \pi}{L}$

where $W, B$, and $U$ are the complex amplitudes and $k$ is the mode number $(n=1,2, \ldots)$.

\subsection{Analysis with the direct proportional control feedback}

If one considers the direct proportional control law (Eq. (26)), the constitutive law (Eq. (21)) becomes

$\left[\begin{array}{c}N \\ M_{\beta} \\ M_{w}\end{array}\right]=\left([C]+g\left[V_{a}\right] \cdot\left[V_{s}\right]^{t}\right)\left[\begin{array}{c}U \\ B \\ k W\end{array}\right](-k \sin (k x))$.

\subsubsection{Condensation of the axial displacement $u$ and the rotation $\beta$}

As is usual, the axial inertia effect is neglected in this analysis, allowing us to reduce the number of generalized displacements $(u, \beta, w)$ to one $w$. From the virtual work principle, after integrating by parts Eq. (37), the mechanical conservation laws are derived as

$\left\{\begin{array}{l}M_{\beta}^{\prime}-T=0, \quad(\mathrm{a}) \\ M_{w}^{\prime \prime}-T^{\prime}-\omega^{2} w(\rho S)_{e q} \ddot{w}=0 .\end{array}\right.$
By inserting Eqs. (15) and (36) into Eqs. (41)(a) and (41)(b), the following equations are obtained in which the unknowns are reduced to $U, B$, and $W$.

$$
\left\{\begin{array}{c}
{\left[(E S)_{e q}-g\right] U+\frac{h_{v}}{2}(\alpha-g) B=H(\alpha-g) k W \quad(\text { a })} \\
-\frac{h_{v}}{2}(\alpha+g) k^{2} U-\left\{\left[(E I)_{\beta e q}+g\left(\frac{h_{v}}{2}\right)^{2}\right] k^{2}+G_{v}(\omega) S_{v}\right\} \\
\times B=\left[G_{v}(\omega) S_{v}+\left(\gamma_{w e q}-g \frac{h_{v}}{2} H\right) k^{2}\right] k W . \quad \text { (b) }
\end{array}\right.
$$

From Eq. (42), the amplitudes $U, B$, and $W$ can be expressed only in terms of $W$ :

$\left[\begin{array}{c}U \\ B \\ k W\end{array}\right]=\left[R_{\text {mode }}\right] k W$

with

$\left[R_{\text {mode }}\right]=\left[\begin{array}{c}U_{\text {mode }} \\ B_{\text {mode }} \\ 1\end{array}\right]$

where

$$
\left\{\begin{array}{l}
U_{\text {mode }} \\
=\frac{2 \frac{H}{h_{v}}\left\{\left[(E I)_{\beta e q}+g\left(\frac{h_{v}}{2}\right)^{2}\right] k^{2}+G_{v}(\omega) S_{v}\right\}+G_{v}(\omega) S_{v}+\left(\gamma_{\text {weq }}-g \frac{h_{v}}{2} H\right) k^{2}}{\frac{(E)_{e q}-g}{\frac{h_{v}}{2}(\alpha-g)}\left\{\left[(E I)_{\beta e q}+g\left(\frac{h_{v}}{2}\right)^{2}\right] k^{2}+G_{v}(\omega) S_{v}\right\}-\frac{h_{v}}{2}(\alpha+g) k^{2}} \\
B_{\text {mode }} \\
=\frac{G_{v}(\omega) S_{v}+\left[\gamma_{\text {weq }}+\frac{h_{v}}{2} H\left(\frac{\alpha^{2}-g^{2}}{(E S)_{e q}-g}-g\right)\right] k^{2}}{-G_{v}(\omega) S_{v}+\left[\left(\frac{h_{v}}{2}\right)^{2}\left(\frac{\alpha^{2}-g^{2}}{\left(E S S_{e q}-g\right.}-g\right)-(E I)_{\beta e q}\right] k^{2}} .
\end{array}\right.
$$

Since the shear modulus $G_{v}(\omega)$ appears in its expression, $\left[R_{\text {mode }}\right]$ is complex and depends on $\omega$.

\subsubsection{Complex eigenfrequency}

To derive the eigenfrequency, the variational Eq. (37) is used, in conjunction with the condensation of $u$ and $\beta$. The following virtual displacements are considered:

$\delta u=\bar{u}=\bar{U} \cos (k x), \quad \delta w=\bar{w}=\bar{W} \sin (k x)$,

$\delta \beta=\bar{\beta}=\bar{B} \cos (k x)$

where $\bar{X}$ is the conjugate complex of $X$.

So, introducing Eqs. (43), (44), (36) and (46) into Eq. (37) provides the following expression:

$\omega^{2}=\frac{k^{4}\left[\overline{R_{\text {mode }}}\right]^{t}\left([C]+g\left[V_{a}\right] \cdot\left[V_{s}\right]^{t}\right)\left[R_{\text {mode }}\right]+k^{2} S_{v} G_{v}(\omega)\left|B_{\text {mode }}+1\right|^{2}}{(\rho S)_{e q}}$.

\subsubsection{Approximation of the complex frequency}

The formula (Eq. (47)) does not provide an explicit expression of the eigenfrequency since $\omega$ depends on the mode itself and the shear modulus. For simplification and clarity, we assume that the shear modulus of the central layer is constant. These assumptions, often used in the open literature, are not realistic, but could be used to derive the first estimation of the eigenfrequency.

Another approximation can be performed when neglecting the influence of the material damping $\eta_{v}$ in the vector $\left[R_{\text {mode }}\right.$ ], i.e. by replacing $G_{v}(\omega)$ by $G_{v}{ }^{R}$ in Eqs. (45) and (44) and then the mode is real and one gets the following expression of the eigenfrequency and of the loss factor:

$\left\{\begin{array}{l}\Omega^{2}=\frac{k^{4}\left[\overline{R_{\text {mode }}}\right]^{t}\left([C]+g\left[V_{a}\right] \cdot\left[V_{s}\right]^{t}\right)\left[R_{\text {mode }}\right]+k^{2} S_{v} G_{v}{ }^{R}\left|B_{\text {mode }}+1\right|^{2}}{(\rho S)_{e q}} \\ \frac{\eta}{\eta_{v}}=\frac{k^{2} S_{v} G_{v}^{R}\left(1+B_{\text {mode }}\right)^{2}}{\Omega^{2}(\rho S)_{e q}} .\end{array}\right.$ 
Notice here that the modal damping is proportional to the viscoelastic damping and that the control gain $g$ can modify this damping through the mode $\left(B_{\text {mode }}\right)$ and the pulsation $\Omega$.

\subsubsection{Accounting for electrode effect}

If one considers the electrode effect with the direct proportional control law (Eq. (26)), the constitutive law (Eq. (31)) becomes this time

$$
\left[\begin{array}{c}
N \\
M_{\beta} \\
M_{w}
\end{array}\right]=\left[C_{\text {elastic }}\right]\left[\begin{array}{c}
U \\
B \\
k W
\end{array}\right](-k \sin (k x))+\alpha\left[V_{\text {equi }}\right] \Phi
$$

with

$\Phi=\left(U+\frac{h_{v}}{2} B-H k W\right)\left((-1)^{n}-1\right)$.

The condensation of the axial displacement $u$ and the rotation $\beta$ lead this time to a new form of the amplitude $U, B$, and $W$ defined by Eqs. (43) and (44) and with $U_{\text {mode }}, B_{\text {mode }}$ defined as

$$
\left\{\begin{array}{l}
U_{\text {mode }}=\frac{b f-e c}{e a-b d} \\
B_{\text {mode }}=\frac{a f-d c}{b d-a e}
\end{array}\right.
$$

with

$$
\left\{\begin{array}{l}
a=\frac{1}{2} L k^{2}(E S)_{\text {mec }}+\frac{\left(1-G_{c}\right) \alpha\left((-1)^{n}-1\right)^{2}}{L} \\
b=\frac{h_{v}\left(1-G_{c}\right) \alpha\left((-1)^{n}-1\right)^{2}}{2 L} \\
c=\frac{-H\left(1-G_{c}\right) \alpha\left((-1)^{n}-1\right)^{2}}{L} \\
d=\frac{h_{v}\left(1+G_{c}\right) \alpha\left((-1)^{n}-1\right)^{2}}{2 L} \\
e=\frac{1}{2} L\left(k^{2}(E I)_{\beta}+G_{r} S_{v}\right)+\frac{h_{v}^{2}\left(1+G_{c}\right) \alpha\left((-1)^{n}-1\right)^{2}}{4 L} \\
f=\frac{1}{2} L\left(k^{2} \gamma_{w}+G_{r} S_{v}\right)-\frac{H h_{v}\left(1+G_{c}\right) \alpha\left((-1)^{n}-1\right)^{2}}{2 L} .
\end{array}\right.
$$

Using a similar procedure as in Section 3.1.2, one can derive the eigenfrequency by introducing Eqs. (43), (44), (36), (51) and (46) into Eq. (37). One gets the following expression:

$\omega^{2}=\frac{2 k^{2}\left(g U_{\text {mode }}+h B_{\text {mode }}+\mathrm{i}\right)}{(\rho S)_{e q} L}$

where

$$
\left\{\begin{array}{l}
g=\frac{-H\left(1+G_{c}\right) \alpha\left((-1)^{n}-1\right)^{2}}{L} \\
h=\frac{1}{2} L\left(k^{2} \gamma_{w}+G_{r} S_{v}\right)-\frac{H h_{v}\left(1+G_{c}\right) \alpha\left((-1)^{n}-1\right)^{2}}{2 L} \\
i=\frac{1}{2} L\left(k^{2}(E I)_{\text {mec }}+G_{r} S_{v}\right)+\frac{H^{2}\left(1+G_{c}\right) \alpha\left((-1)^{n}-1\right)^{2}}{L} .
\end{array}\right.
$$

\subsection{Analysis with velocity feedback control}

Considering the velocity derivative control law (Eq. (29)), the constitutive law (Eq. (30)) becomes

$$
\left[\begin{array}{c}
N \\
M_{\beta} \\
M_{w}
\end{array}\right]=\left([C]-\mathrm{i} \omega g\left[V_{a}\right] \cdot\left[V_{s}\right]^{t}\right)\left[\begin{array}{c}
U \\
B \\
k W
\end{array}\right](-k \sin (k x)) .
$$

\subsubsection{Condensation of the axial displacement $u$ and the rotation $\beta$}

Considering the formerly defined constitutive law, and using a similar procedure as defined in Section 3.1.1, one gets the new form of amplitude $U, B$, and $W$ defined by Eq. (44), (43) and with $U_{\text {mode }}$, $B_{\text {mode }}$ defined by

$$
\left\{\begin{array}{l}
U_{\text {mode }} \\
=\frac{2 \frac{H}{h_{v}}\left\{\left[(E I)_{\beta e q}-\mathrm{i} \omega g\left(\frac{h_{v}}{2}\right)^{2}\right] k^{2}+G_{v}(\omega) S_{v}\right\}+G_{v}(\omega) S_{v}+\left(\gamma_{\text {weq }}+\mathrm{i} \omega g \frac{h_{v}}{2} H\right) k^{2}}{2 \frac{(E S)_{\text {eq }}}{h_{v} \alpha}\left\{\left[(E I)_{\beta e q}-\mathrm{i} \omega g\left(\frac{h_{v}}{2}\right)^{2}\right] k^{2}+G_{v}(\omega) S_{v}\right\}-\frac{h_{v}}{2}(\alpha-\mathrm{i} \omega g) k^{2}} \\
B_{\text {mode }}=\frac{G_{v}(\omega) S_{v}+\left[\gamma_{\text {weq }}+\frac{h_{v}}{2} H\left(\frac{\left(\alpha^{2}-i \omega \alpha\right)}{(E S)}+\mathrm{i} \omega g\right)\right] k^{2}}{-G_{v}(\omega) S_{v}+\left[\left(\frac{h_{v}}{2}\right)^{2}\left(\frac{\left(\alpha^{2}-\mathrm{i} \omega \alpha g\right)}{(E S)}+\mathrm{i} \omega g\right)-(E I)_{\beta e q}\right] k^{2}} .
\end{array}\right.
$$

\subsubsection{Complex eigenfrequency}

To derive the eigenfrequency, a similar procedure as defined in Section 3.1.2 is used. So, introducing Eqs. (43), (44) and (46) into Eq. (37), and replacing [ $N, M_{\beta}, M_{w}$ ] by Eq. (55) and $T$ by Eq. (36), provides the following expression of $\omega$. $U_{\text {mode }}, B_{\text {mode }}$ are defined by Eq. (56):

$\omega^{2}=\frac{k^{4}\left[\overline{R_{\text {mode }}}\right]^{t}\left([C]-\mathrm{i} \omega g\left[V_{a}\right] \cdot\left[V_{s}\right]^{t}\right)\left[R_{\text {mode }}\right]+k^{2} S_{v} G_{v}(\omega)\left|B_{\text {mode }}+1\right|^{2}}{(\rho S)_{\text {eq }}}$.

From this equation, three major structural effects are noticeable:

- The elastic effect is defined essentially by the term " $\left[\overline{R_{\text {mode }}}\right]^{t}$ ([C]) $\left[R_{\text {mode }}\right] "$

- The passive damping introduced by the viscoelastic layer is expressed by the imaginary part of " $S_{v} G_{v}(\omega)\left|B_{\text {mode }}+1\right|^{2 \text { ". }}$

- The active damping is expressed by the term " $\left[\overline{R_{\text {mode }}}\right]^{t}\left(\omega g\left[V_{a}\right]\right.$ .[$\left.\left[V_{s}\right]^{t}\right)\left[R_{\text {mode }}\right]^{\prime \prime}$.

For small values of passive and active damping, the total damping is the sum of active and passive damping.

\subsubsection{Accounting for the electrode effect}

If one considers the electrode effect with the velocity feedback control law (Eq. (29)), the constitutive law (Eq. (33)) becomes this time

$\left[\begin{array}{c}N \\ M_{\beta} \\ M_{w}\end{array}\right]=\left[C_{\text {elastique }}\right]\left[\begin{array}{c}U \\ B \\ k W\end{array}\right](-k \sin (k x))+[A] \Phi+[\Gamma] \dot{\Phi}$

where $[A]$ and $[\Gamma]$ are defined by Eq. (34) and $\Phi$ by Eq. (50).

The condensation of the axial displacement $u$ and the rotation $\beta$ lead to a new form of the amplitude $U, B$, and $W$ defined by Eqs. (43), (44) and (51) with this time in the last equation

$$
\left\{\begin{array}{l}
a=\frac{1}{2} L k^{2}(E S)_{\text {mec }}+\frac{\left(1+\mathrm{i} \omega G_{v}\right) \alpha\left((-1)^{n}-1\right)^{2}}{L} \\
b=\frac{h_{v}\left(1+\mathrm{i} \omega G_{v}\right) \alpha\left((-1)^{n}-1\right)^{2}}{2 L} \\
c=\frac{-H\left(1+\mathrm{i} \omega G_{v}\right) \alpha\left((-1)^{n}-1\right)^{2}}{L} \\
d=\frac{h_{v}\left(1-\mathrm{i} \omega G_{v}\right) \alpha\left((-1)^{n}-1\right)^{2}}{2 L} \\
e=\frac{1}{2} L\left(k^{2}(E I)_{\beta}+G_{r} S_{v}\right)+\frac{h_{v}^{2}\left(1-\mathrm{i} \omega G_{v}\right) \alpha\left((-1)^{n}-1\right)^{2}}{4 L} \\
f=\frac{1}{2} L\left(k^{2} \gamma_{w}+G_{r} S_{v}\right)-\frac{H h_{v}\left(1-\mathrm{i} \omega G_{v}\right) \alpha\left((-1)^{n}-1\right)^{2}}{2 L} .
\end{array}\right.
$$


Using a similar procedure as in Sections 3.1.2 and 3.1.4, one can derive the eigenfrequency. Introducing Eqs. (43), (44), (36), (51) and (46) into Eq. (37) provides the following expression:

$\omega^{2}=\frac{2 k^{2}\left(g U_{\text {mode }}+h B_{\text {mode }}+\mathrm{i}\right)}{(\rho S)_{e q} L}$

where

$$
\left\{\begin{array}{l}
g=\frac{-H\left(1-\mathrm{i} \omega G_{v}\right) \alpha\left((-1)^{n}-1\right)^{2}}{L} \\
h=\frac{1}{2} L\left(k^{2} \gamma_{w}+G_{r} S_{v}\right)-\frac{H h_{v}\left(1-\mathrm{i} \omega G_{v}\right) \alpha\left((-1)^{n}-1\right)^{2}}{2 L} \\
i=\frac{1}{2} L\left(k^{2}(E I)_{\text {mec }}+G_{r} S_{v}\right)+\frac{H^{2}\left(1-\mathrm{i} \omega G_{v}\right) \alpha\left((-1)^{n}-1\right)^{2}}{L} .
\end{array}\right.
$$

\section{Results and discussion}

For the numerical studies, the geometrical data of the sandwich beam are fixed as follows: $h=10 \mathrm{~mm}, L=50 \mathrm{~h}, h_{e}=6 \frac{h}{15}$, $h_{v}=h_{s}=h_{a}=\frac{h}{15}$.

The densities of materials are, for the elastic layers, $\rho_{e}=$ $2040 \mathrm{~kg} / \mathrm{m}^{3}$, for the viscoelastic core $\rho_{v}=1200 \mathrm{~kg} / \mathrm{m}^{3}$, and for the piezoelectric layers $\rho_{p}=7500 \mathrm{~kg} / \mathrm{m}^{3}$.

The elastic shear modulus is fixed to $G_{e}=25 \mathrm{GPa}$. As for the material properties of the viscoelastic layer, several values will be considered. The constitutive equations of the PZT4 orthotropic piezoelectric layers may be summarized as followed in classical matrix form:

$$
\left\{\begin{array}{l}
\sigma_{1} \\
\sigma_{2} \\
\sigma_{3} \\
\sigma_{4} \\
\sigma_{5} \\
\sigma_{6} \\
D_{1} \\
D_{2} \\
D_{3}
\end{array}\right\}
$$$$
=\left[\begin{array}{cccccc|ccc}
C_{11} & C_{12} & C_{13} & 0 & 0 & 0 & 0 & 0 & -e_{31} \\
C_{12} & C_{22} & C_{23} & 0 & 0 & 0 & 0 & 0 & -e_{32} \\
C_{13} & C_{23} & C_{33} & 0 & 0 & 0 & 0 & 0 & -e_{33} \\
0 & 0 & 0 & C_{44} & 0 & 0 & 0 & -e_{24} & 0 \\
0 & 0 & 0 & 0 & C_{55} & 0 & -e_{15} & 0 & 0 \\
0 & 0 & 0 & 0 & 0 & C_{66} & 0 & 0 & 0 \\
\hline 0 & 0 & 0 & 0 & e_{15} & 0 & \epsilon_{11} & 0 & 0 \\
0 & 0 & 0 & e_{24} & 0 & 0 & 0 & \epsilon_{22} & 0 \\
e_{31} & e_{32} & e_{33} & 0 & 0 & 0 & 0 & 0 & \epsilon_{33}
\end{array}\right]
$$$$
\times\left\{\begin{array}{l}
\epsilon_{1} \\
\epsilon_{2} \\
\epsilon_{3} \\
\gamma_{23} \\
\gamma_{13} \\
\gamma_{12} \\
E_{1} \\
E_{2} \\
E_{3}
\end{array}\right\}
$$

where

$$
\begin{cases}C_{11}=C_{22}=139.0 \mathrm{GPa} ; & C_{33}=115.3 \mathrm{GPa} \\ C_{13}=C_{23}=74.3 \mathrm{GPa} ; & C_{12}=77.8 \mathrm{GPa} \\ C_{44}=C_{55}=25.6 \mathrm{GPa} ; & C_{66}=30.6 \mathrm{GPa} \\ e_{31}=e_{32}=-5.21 \mathrm{C} / \mathrm{m}^{2} ; & e_{33}=15.1 \mathrm{C} / \mathrm{m}^{2} ; \\ e_{15}=e_{24}=12.7 \mathrm{C} / \mathrm{m}^{2} & \\ \epsilon_{11}=\epsilon_{22}=1.31 \mathrm{e}^{-8} \mathrm{~F} / \mathrm{m} ; & \epsilon_{33}=1.15 \mathrm{e}^{-8} \mathrm{~F} / \mathrm{m} .\end{cases}
$$

\subsection{Numerical validation of the model}

In order to validate the different assumptions of the present analytical model (Section 2), the direct frequency response method with a 2D finite element (FE) in ABAQUS Standard Code is applied to obtain the first modal properties (flexural frequencies and associated damping ratios) of the sandwich beam subjected to a direct proportional feedback control law. Note that this kind of control is the only one available in the ABAQUS code. The sandwich, Fig. 2, is composed of 240 8-node plane strain elements with a reduced integration. A steady-state linear dynamic analysis procedure ABAQUS [34] to monitor the linear response of beam structure subjected to continuous harmonic excitation has been used.

Table 1 presents the values of frequency and loss factor obtained from ABAQUS FE code and those from the present model using the complex $\left[R_{\text {mode }}\right]$ (Eq. (47)) for different values of $g$ (gain) and $G_{v}$ (shear modulus of the core). In all presented situations, the analytical results (Eq. (47)) are very close to the numerical ones.

\subsection{Validity range of approximated frequency}

In order to analyse the impact of considering $\left[R_{\text {mode }}\right]$ real (Eq. (48)) or complex (Eq. (47)) we compare the first eigenvalue, using the software mathematic package Maple. The effects of different viscoelastic cores (shear moduli) as well as different direct control gains were analyzed.

\subsubsection{Analysis with no control effect $(g=0)$}

In this part, the direct piezoelectric control gain is fixed ( $g=0)$. Results with three different viscoelastic shear modulus $G_{v}^{R}$ and two different viscoelastic material damping $\left(\eta_{v}=0.5\right.$ and $\eta_{v}=1$ in Table 3) are considered.

It appears clearly that ignoring the complex part of $\left[R_{\text {mode }}\right]$ leads to unsatisfactory results in some identified cases. The layer discrepancies are obtained in the case of a relatively stiff core $\left(G_{v}^{R} / G_{e}=10^{-3}\right)$ or of a large material damping $\left(\eta_{v}=1.0\right)$. These differences concern the loss factor, while the eigenfrequencies are not very sensitive to the assumption of a real mode. This assumption of a real mode leads to a good approximation if $G_{v}^{R} / G_{e} \leq 10^{-4}, \eta_{v} \leq 0.5$.

\subsubsection{Analysis with various direct control gains}

In this part, the viscoelastic shear modulus $\left(G_{v}=2.5 \mathrm{MPa}\right)$ and the elastic shear modulus $\left(G_{e}=25 \mathrm{GPa}\right)$ are fixed. This value of the viscoelastic shear modulus is more or less representative of real materials. For the tested values of the material loss factors $\left(\eta_{v}=0.1,0.5,1\right)$, the assumption of a real mode $\left[R_{\text {mode }}\right]$ induces at most an error less than $2 \%$, in the range $-20 \leq g \leq 50$. Out of this range, the system tends to be unstable.

From Fig. 4, one observes that the frequency $\Omega$ varies more or less linearly, with respect to the control gain, in the range $-10 \leq g \leq 40$. Indeed, this control law looks like an elastic law. It modifies mainly the stiffness of the structure and therefore the eigenfrequencies. The modal loss factors $\eta$ depend on the control only via the changes in the frequencies, and its variation becomes significant only for large values of the control gain $g$, Fig. 5.

In a second part one considers the equipotentiality condition imposed by an electrode. One can see for the tested values of the material loss factors $\left(\eta_{v}=0.1,0.5,1\right)$ that the effect of the active control is weak. Indeed if one considers value of the control gain $g$ in the range $[-1,1]$ the modal properties with and without electrode are similar (Tables 1 and 2). Then one consider more important values for the control gain $g$ and we test for a fixed value from the loss factor $\left(\eta_{v}=0.5\right)$ the importance of taking into account the equipotentiality. In Fig. 3 one can clearly see that if $|g|$ is important the equipotentiality condition leads to smaller value of the eigenfrequency. 


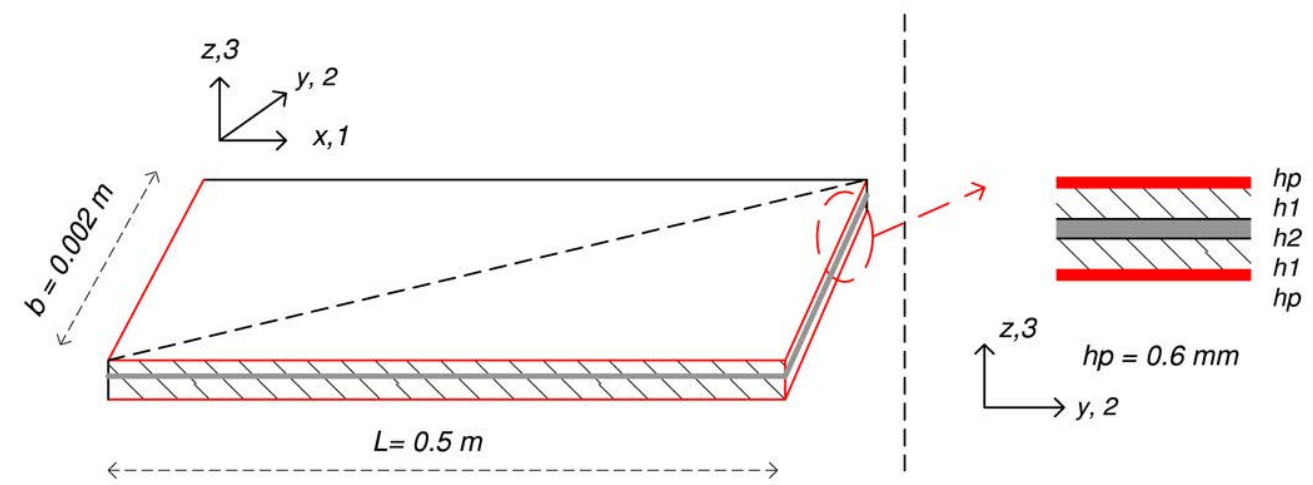

Fig. 2. Dimensions of the five-layer sandwich structure.

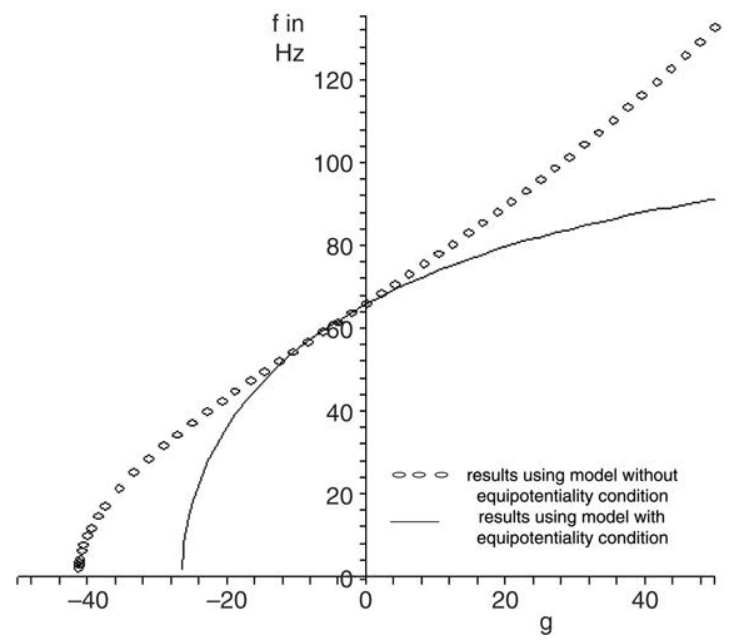

Fig. 3. Variation of the frequency with and without equipotentiality condition $\eta=0.5$ direct proportional control $g$ varying. $G_{v}=2.5 \mathrm{MPa}, G_{e}=25 \mathrm{GPa}$.

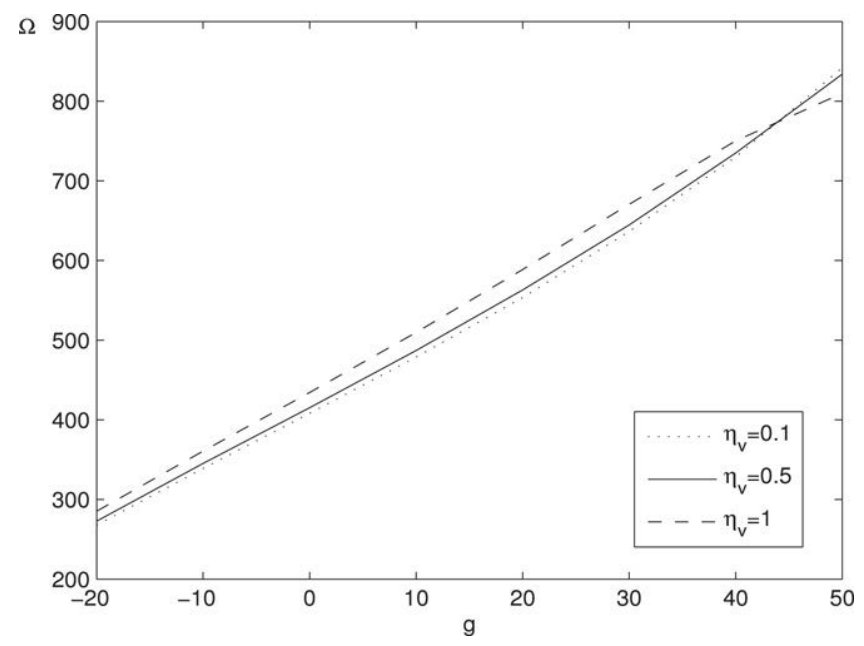

Fig. 4. First eigenfrequency $\Omega$ as a function of the direct proportional control gain g. $G_{v}=2.5 \mathrm{MPa}, G_{e}=25 \mathrm{GPa}$.

\subsubsection{Analysis with various velocity feedback control gains}

In this part, the same moduli $\left(G_{v}=2.5 \mathrm{MPa}\right.$ and $G_{e}=$ $25 \mathrm{GPa}$ ) as in 4.2.2 are considered. From Figs. 6 and 7, one sees that this control law has a strong influence on the structural damping properties, but not on the eigenfrequencies. In the considered range $0 \leq g \leq 0.025$, the loss factor increases linearly with the control gain. Moreover, the curves of Fig. 7 are more or less parallel.
Table 1

Comparison of the beam model (analytical) with a 2D finite element analysis (numerical)

\begin{tabular}{lllllll}
\hline$g$ & $G_{v}(\mathrm{MPa})$ & & $f(\mathrm{~Hz})$ & & $\eta$ \\
& & Analytical & Numerical & & Analytical & Numerical \\
\hline \multirow{3}{*}{1} & 2.5 & 67.2 & 67.2 & 0.171 & 0.171 \\
& 25 & 86.4 & 86.5 & 0.038 & 0.038 \\
& 2500 & 90.2 & 90.3 & 0.00043 & 0.00042 \\
0 & 2.5 & 66.2 & 66.1 & 0.169 & 0.169 \\
& 25 & 84.8 & 84.7 & 0.038 & 0.039 \\
& 2500 & 88.2 & 88.1 & 0.00042 & 0.00045 \\
& 2.5 & 65.1 & 65 & 0.167 & 0.168 \\
-1 & 25 & 82.9 & 82.9 & 0.037 & 0.037 \\
& 2500 & 86.2 & 86.2 & 0.00041 & 0.00043
\end{tabular}

$\eta_{v}=0.5$. Direct proportional control law.

Table 2

Comparison of the beam model (analytical) with a 2D finite element analysis (numerical)

\begin{tabular}{lllllll}
\hline$g$ & $G_{v}(\mathrm{MPa})$ & & $f(\mathrm{~Hz})$ & & $\eta$ \\
& & Analytical & Numerical & & Analytical & Numerical \\
\hline \multirow{3}{*}{1} & 2.5 & 66.9 & 66.8 & 0.170 & 0.176 \\
& 25 & 85.9 & 85.9 & 0.038 & 0.038 \\
& 2500 & 89.5 & 89.6 & 0.00043 & 0.00042 \\
& 2.5 & 66.0 & 66.0 & 0.169 & 0.172 \\
0 & 25 & 84.4 & 84.5 & 0.037 & 0.037 \\
& 2500 & 87.9 & 87.8 & 0.00042 & 0.00045 \\
& 2.5 & 65.1 & 65.1 & 0.167 & 0.168 \\
-1 & 25 & 83.0 & 83.0 & 0.037 & 0.037 \\
& 2500 & 86.3 & 86.2 & 0.00041 & 0.00042
\end{tabular}

$\eta_{v}=0.5$. Direct proportional control law and equipotentiality condition.

This means that the contributions of active and passive damping are nearly additive.

In a second part one considers the equipotentiality condition imposed by an electrode. We tested different values of the material loss factors $\left(\eta_{v}=0.1,0.5,1\right)$ and of the gain control $g$ but we could not observe any stability range.

\section{Conclusion}

In this paper, simple models and analytical modal solutions for piezoelectric/elastic/viscoelastic/elastic/piezoelectric beams have been presented. Direct proportional feedback as well as a velocity feedback control law have been considered, and constitutive equations of the whole controlled sandwich beam have been established. The eigenfrequencies and the loss factors have been defined for this hybrid damped system. As expected, the direct control law modifies the stiffness and the frequencies while the second control law influences mainly the damping properties of the system. 
Table 3

Purely passive damping $(g=0)$

\begin{tabular}{|c|c|c|c|c|c|}
\hline$\eta_{v}$ & $G_{v}^{R}(\mathrm{MPa})$ & $\begin{array}{l}f(\mathrm{~Hz}) \text { with } \\
{\left[R_{\text {mode }}\right] \text { real }}\end{array}$ & $\begin{array}{l}f(\mathrm{~Hz}) \text { with } \\
{\left[R_{\text {mode }}\right] \text { complex }(\%)}\end{array}$ & $\begin{array}{l}\eta \text { with } \\
{\left[R_{\text {mode }}\right] \text { real }}\end{array}$ & $\begin{array}{l}\eta \text { with } \\
{\left[R_{\text {mode }}\right] \text { complex }(\%)}\end{array}$ \\
\hline \multirow{3}{*}{0.5} & 0.25 & 44.0 & $43.9(0.2)$ & 0.108 & 0.107 (0.9) \\
\hline & 2.5 & 65.0 & $66.1(1.7)$ & 0.167 & $0.169(1.2)$ \\
\hline & 25 & 84.1 & $84.8(0.8)$ & 0.032 & $0.038(15.8)$ \\
\hline \multirow{3}{*}{1.0} & 0.25 & 43.9 & $44.2(0.7)$ & 0.214 & $0.212(0.9)$ \\
\hline & 2.5 & 65.6 & $69.1(5.1)$ & 0.26 & $0.273(4.8)$ \\
\hline & 25 & 84.8 & $85.9(1.3)$ & 0.028 & $0.049(42.9)$ \\
\hline
\end{tabular}

The influence of the real mode assumption on frequency and modal damping. First vibration mode.

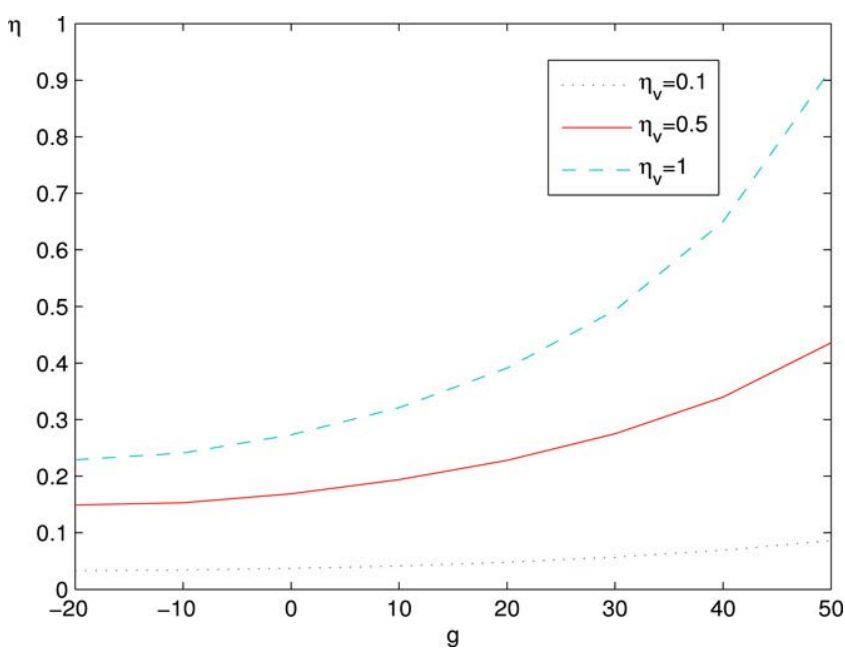

Fig. 5. The damping $\eta$ of the first mode as a function of the direct proportional control gain $g . G_{v}=2.5 \mathrm{MPa}, G_{e}=25 \mathrm{GPa}$.

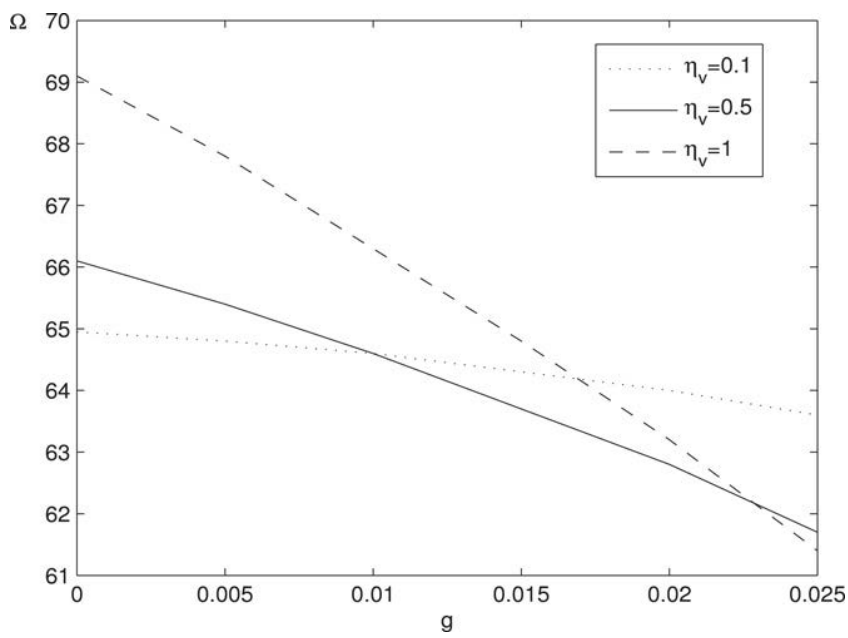

Fig. 6. First eigenfrequency $\Omega$ as a function of the velocity feedback control gain $g$. $G_{v}=2.5 \mathrm{MPa}, G_{e}=25 \mathrm{GPa}$.

\section{Acknowledgements}

The authors acknowledge the financial support of the Luxembourgish National Research Fund (FNR-MAT-08-01 ADYMA) and the European FP6 ERA-NET Materials (MATERA).

\section{References}

[1] Kerwin EM. Damping of flexural waves by a constrained viscoelastic layer. J Acoust Soc Am 1959;31(7):952-62.

[2] Ross D, Ungar E, Kerwin EM. Damping of plate flexural vibrations by means of viscoelastic laminae. In: Ruzicka JE, editor. Structural damping. 1959.

[3] Ambartsumian SA. On a theory of bending of anisotropic plates. Prikl Mat Mekh $1958 ; 22: 226-37$

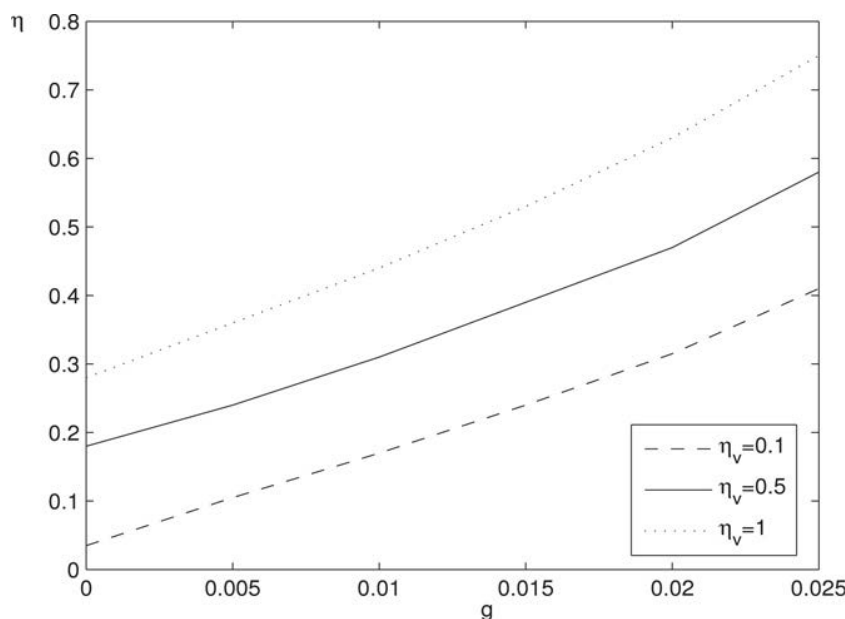

Fig. 7. The first loss factor $\eta$ as a function of the velocity feedback control gain $g$. $G_{v}=2.5 \mathrm{MPa}, G_{e}=25 \mathrm{GPa}$.

[4] Carrera E. Historical review of zig-zag theories for multilayered plates and shells. Appl Mech Rev 2003;56:287-308.

[5] $\mathrm{Hu} \mathrm{H}$, Belouettar S, Potier-Ferry M, Daya EM. Review and assessment of various theories for modeling sandwich composites. Compos Struct 2008; 84(3):282-92.

[6] Soni ML. Finite element analysis of viscoelastically damped sandwich structures. Shock Vibration Bull 1981;55(1):97-109.

[7] Bathe KJ. Finite element procedures in engineering analysis. NJ: Prentice-Hall 1982.

[8] Rikards R, Chate A, Barkanov E. Finite element analysis of damping the vibrations of laminated composites. Comput Struct 1993;47(6):1005-15.

[9] Chen X, Chen HL, Hu Le. Damping prediction of sandwich structures by orderreduction-iteration approach. J Sound Vibration 1999;222(5):803-12.

[10] Daya EM, Potier-Ferry M. A numerical method for nonlinear eigenvalue problems: Application to vibrations of viscoelastic structures. Comput Struct 2001;79:533-41.

[11] Duigou L, Daya EM, Potier-Ferry M. Iterative algorithms for non-linear eigenvalue problems. Application to vibrations of viscoelastic shells. Comput Methods Appl Mech Eng 2003;192:1323-35.

[12] Rao SS, Sunar M. Recent advances in sensing and control of flexible structures via piezoelectric material technology. Appl Mech Rev 1999;52:1-16.

[13] Nakra BC. Vibration control with viscoelastic materials. Shock Vibration Diges 1976;8:3-12.

[14] Nakra BC. Vibration control with viscoelastic materials-ii. Shock Vibration Digest 1981;13:17-20.

[15] Nakra BC. Vibration control with viscoelastic materials-iii. Shock Vibration Digest 1984; 16:17-22.

[16] Torvik PJ. The analysis and design of constrained layer damping treatments. In Proceedings. ASME winter annual meeting. Damping applications for vibration control. 1980. p. 85-112.

[17] Mead DJ. A comparison of some equations for the flexural vibration of damped sandwich beams. J Sound Vibration 1982;83:363-77.

[18] Lee CK. Theory of laminated piezoelectric plates for the design of distributed sensors/actuators. Part i: Governing equations and reciprocal relationships. J Acoust Am Soc 1990;87:1144-58.

[19] Crawley EF, Lazarus KB. Induced strain actuation of isotropic and anisotropic plates. Amer Institute Aeronaut Astronaut 1991;29(6):944-51.

[20] Preumont A. Vibration control of active structures. Dordrecht: Kluwer Academic Publishers; 1997.

[21] Kapuria S, Ahmed A, Dumir PC. An efficient coupled zigzag theory for dynamic analysis of piezoelectric composite and sandwich beams with damping. J Sound Vibration 2005;279:345-71. 
[22] Maurini C, Pouget J, dell'Isola F. On a model of layered piezoelectric beams including transverse stress effect. Internat J Solids Structures 2004;41: 4473-502.

[23] Liew KM, He XQ, Kitipornchai S. Finite element method for the feedback control of fgm shells in the frequency domain via piezoelectric sensors and actuators. Comput Methods Appl Mech Eng 2004;193:257-73.

[24] Park CH, Baz A. Vibration control of bending modes of plates using active constrained layer damping. J Sound Vibration 1999;227:711-34.

[25] Varadan VV, Lim YH, Varadan VK. Closed loop finite-element modeling of active/passive damping in structural vibration control. Smart Mater Struct 1996;227(5):685-94.

[26] Balamurugan V, Narayanan S. Finite element formulation and active vibration control study on beams using smart constrained layer damping (scld) treatment. J Sound Vibration 2002;249:227-50.

[27] Ray MC, Reddy JN. Active control of laminated cylindrical shells using piezoelectric fiber reinforced composites. Compos Sci Technol 2005;65: 1226-36.

[28] Vasques CMA, Dias Rodrigues J. Combined feedback/feedforward active control of vibration of beams with ACLD treatments: Numerical simulation. Comput Struct 2008;86(3-5):292-306.

[29] Heyliger P, Brooks S. Exact solutions for laminated piezoelectric plates in cylindrical bending. J Appl Mech 1996;63:903-10.
[30] Vel S, Mewer RC, Batra RC. Analytical solution for the cylindrical bending vibration of piezoelectric composite plates. Internat J Solids Structures 2004; 41:1625-43.

[31] Cupial P, Niziol J. Vibration and damping analysis of three-layered composite plate with viscoelastic mid-layer. J Sound Vibration 1995;183(1):99-114.

[32] Franco Correia VM, Aguia Gomes AM, Suleman A. Modelling and design of adaptive composite structures. Comput Methods Appl Mech Eng 2000;185: 325-46.

[33] Duigou L, Daya EM, Potier-Ferry M. Equivalent stiffness and damping of sandwich piezoelectric beams submitted to active control. Smart Mater Struct 2006;15:623-30

[34] ABAQUS Standard. Version 5.8. Pawtucket, RI: Hibbitt, Karlsson \& Sorensen, Inc.; 1998.

[35] De JF, Galucio AC, Ohayon R. Dynamic responses of flexible-link mechanisms with passive/active damping treatment. Comput Struct 2008;86(3-5): 258-265.

[36] Gopinathan SV, Varadan VV, Varadan VK. A review and critique of theories for piezoelectric laminates. Smart Mater Struct 2000;9:24-48.

[37] Duigou L. Modélisation numérique de l'amortissement passif et actif des tôles sandwichs comportant des couches viscoélastiques ou piezoélectriques, Thesis, 2002

[38] Rao DK. Frequency and loss factor of sandwich beams under various boundary conditions. J Mech Eng Sci 1978;20(5):271-82. 